\title{
Columbus Payloads Flow Rate Anomalies
}

\author{
Albino Quaranta ${ }^{1}$, Gaetana Bufano ${ }^{2}$ and Savino De Palo \\ Thales Alenia Space Italia, Turin, Italy, 10146 \\ \& \\ James M. Holt ${ }^{4}$ \\ NASA, Johnson Space Center, Houston, Texas \\ Zoltan Szigetvari ${ }^{5}$ \\ Astrium GmbH, Bremen, Germany, 28199 \\ Sergio Palumberi ${ }^{6}$ \\ VEGA Space GmbH, Germany \\ S. Hinderer ${ }^{7}$ \\ ESA
}

The Columbus Active Thermal Control System (ATCS) is the main thermal bus for the pressurized racks working inside the European laboratory. One of the ATCS goals is to provide proper water flow rate to each payload $(\mathrm{P} / \mathrm{L})$ by controlling actively the pressure drop across the common plenum distribution piping. Overall flow measurement performed by the Water Pump Assembly (WPA) is the only flow rate monitor available at system level and is not part of the feedback control system. At rack activation the flow rate provided by the system is derived on ground by computing the WPA flow increase. With this approach, several anomalies were raised during these 3 years on-orbit, with the indication of low flow rate conditions on the European racks FSL, BioLab, EDR and EPM. This paper reviews the system and P/Ls calibration approach, the anomalies occurred, the engineering evaluation on the measurement approach and the accuracy improvements proposed, the on-orbit test under evaluation with NASA and finally discusses possible short and long term solutions in case of anomaly confirmation.

\footnotetext{
${ }^{1}$ Thermal Engineer, BS-SIT, Strada Antica di Collegno, 246 Torino - Italy/10146

${ }^{2}$ Thermal System Engineer, BS-SIT, Strada Antica di Collegno, 246 Torino - Italy/10146

${ }^{3}$ Thermal Engineer, BS-SIT, Strada Antica di Collegno, 246 Torino - Italy/10146

${ }^{4}$ Subsystem Manager, ISS IATCS, Crew and Thermal Systems Division/EC, 2101 NASA Parkway, Houston, TX 77058

${ }^{5}$ System Engineer, Orbital \& Reusable Systems/ISS Elements, e-mail: Zoltan.Szigetvari@astrium.eads.net

${ }^{6}$ Columbus On-site Engineering Support (COL-EST, Col-CC), e-mail: sergio.palumberi.external@astrium.eads.net

${ }^{7}$ Insert Job Title, Department Name, Address/Mail Stop, and AIAA Member Grade for first author.
}

American Institute of Aeronautics and Astronautics 


\section{Nomenclature}

\begin{tabular}{|c|c|}
\hline$A R$ & $=$ Anomaly Report \\
\hline$A T C S$ & $=$ Active Thermal Control System \\
\hline$B L B$ & $=$ Biolab \\
\hline CHX & $=$ Condensing Heat Exchanger \\
\hline $\mathrm{COL}-\mathrm{CC}$ & $=$ COLumbus Control Center \\
\hline COTS & $=$ Commercial Off-The Shelf \\
\hline$D P S B$ & $=$ Delta Pressure Sensor block \\
\hline$D O Y$ & $=$ Day Of Year \\
\hline$E D R$ & = European Drawer Rack \\
\hline$E P C$ & $=$ Electronic Package Controller \\
\hline$E P M$ & $=$ European Physiology Module \\
\hline$E R-3$ & $=$ Express Rack 3 \\
\hline ESA & $=$ European Space Agency \\
\hline$F C T$ & $=$ Flight Control Team \\
\hline FSL & $=$ Fluid Science Laboratory \\
\hline$G M T$ & $=$ Greenwich Mean Time \\
\hline$H R F$ & $=$ Human Research Facility \\
\hline$H X$ & $=$ Heat eXchanger \\
\hline$I C D$ & $=$ Interface Control Document \\
\hline$I S P R$ & $=$ International Standard Payload Rack \\
\hline ISS & = International Space Station \\
\hline$L T$ & $=$ Low Temperature \\
\hline MT & $=$ Medium Temperature \\
\hline NASA & $=$ National Aeronautics and Space Administration \\
\hline$P I D$ & $=$ Proportional Integrative Derivative \\
\hline$P / L$ & $=$ Payload \\
\hline$Q D$ & $=$ Quick Disconnect \\
\hline$T A S-I$ & $=$ ThalesAlenia Space Italia \\
\hline THMM & $=$ Thermal- Hydraulic Mathematical Model \\
\hline$W F S V$ & $=$ Water Flow Selection Valve \\
\hline$W M V$ & $=$ Water Modulating Valve \\
\hline WOOV & $=$ Water On Off Valve \\
\hline$W P A$ & $=$ Water Pump Assembly \\
\hline$W P U$ & $=$ Water Pump Unit \\
\hline$W T S B$ & Water Temperature Sensor Bloct \\
\hline
\end{tabular}

American Institute of Aeronautics and Astronautics 


\section{Introduction}

Columbus European Laboratory currently hosts 4 ESA and 4 NASA Payloads (P/Ls). They can operate simultaneously within the heat rejection and overall flow budget constraints, respectively of $14.5 \mathrm{~kW}$ and $1050 \mathrm{~kg} / \mathrm{h}$ including both systems and P/Ls. Between inlet and outlet P/L Quick Disconnects (QD) a $42 \pm 2 \mathrm{kPa}$ delta pressure is constantly guaranteed by the active Water Pump Assembly (WPA) whose speed is controlled by a Proportional Integral Derivative (PID) control law. Two other PID control laws act regulating two 3-ways Water Modulating Valves (WMV), controlling supply water temperature for P/Ls $\left(17 \pm 0.3{ }^{\circ} \mathrm{C}\right)$ and for Condensing Heat Exchanger (CHX). Functional schematic representing the Active Thermal Control system (ATCS) is shown here below.

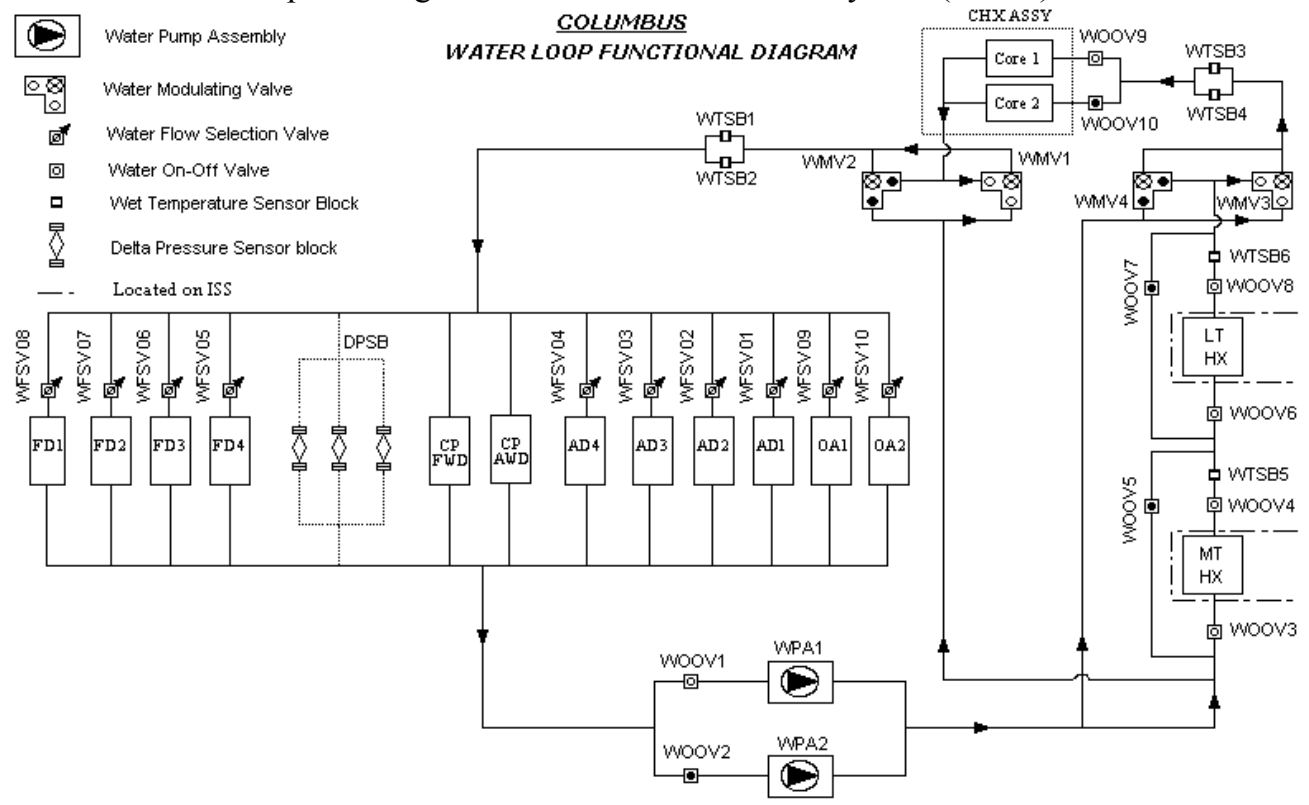

Figure 1 Simplified ATCS schematic

The core element of ATCS is the WPA: it regulates its motor speed to keep the plenum pressure drop within the range $40-44 \mathrm{kPa}$ providing thus the hydraulic conditions required for $\mathrm{P} / \mathrm{Ls}$ and system cold plates.

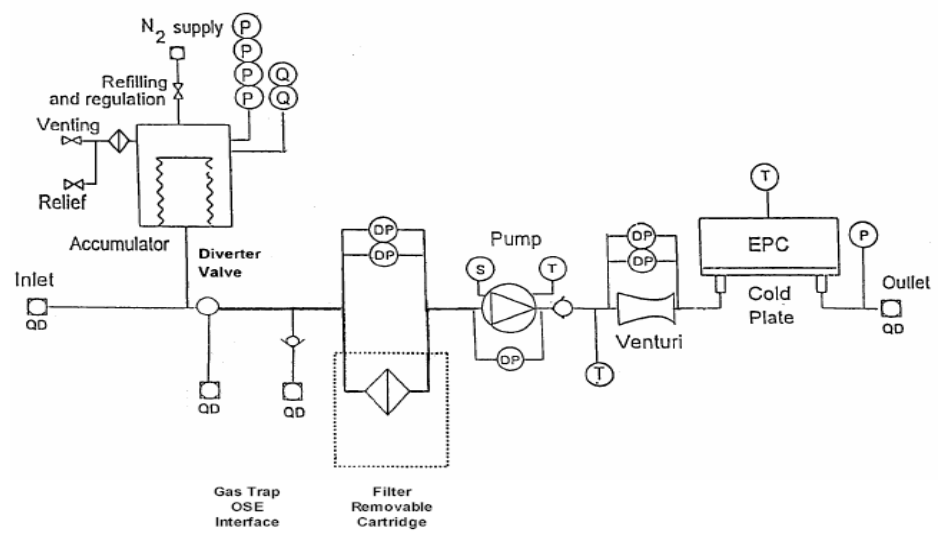

Figure 2 Detailed WPA schematics

Downstream the Water Pump Unit (WPU) there is a calibrated Venturi Flow Meter (VFM). Direct measure of Delta Pressure across the VFM is converted into pump water flow via calibration table, implemented into lookup tables of the WPA software. The Delta Pressure is measured by two different sensors and the delta pressure figures obtained are converted into to two different flow rate estimations, named in the telemetry data Mass Flow and Water Flow.

Venturi Flow Meter is the only flow measurement performed at ATCS subsystem level. As far as P/Ls are concerned, NASA Payloads - Express Rack-3 (ER-3), Human Research Facility 1 (HRF-1) and Human Research Facility 2 (HRF-2) - have internal flow metering systems, while ESA P/Ls do not have this capability. For this reason the only way to estimate flow rate through ESA racks is by computing the WPA flow increasing due to the related Water Flow Selection Valve (WFSV) opening. 


\section{System and Payload calibration approach}

Payloads design and verification is performed accordingly to the Pressurized Payloads Interface Requirement Document. Integrated racks are calibrated on ground such that the delta pressure between the inlet and the outlet, measured at the International Standard Payload Rack (ISPR) self-sealing quick disconnects (QDs), is in the range 40 $\pm 1.4 \mathrm{kPa}$ with the ISPR operated at the calibration flow rate. On the system side, the Columbus ATCS had the requirement to provide for each rack and for any possible configuration, a flow rate in the range of $\pm 10 \%$ with WFSV in fully open conditions and $\pm 25 \%$ with WFSV working with partial stroke.

Hydraulic compatibility between P/Ls and ATCS was verified in the C/D phase, with an extended analysis campaign performed with the ATCS Thermal Hydraulic Mathematical Model (THMM ${ }^{12}$ ). The ATCS model was built, a test campaign was performed mounting, in ISPRs locations, proper calibrated Payload Simulators with the same Delta Pressure / Flow Rate hydraulic characteristic as actual Payloads. On ground tests did not report any flow rate issue on Payload simulators ${ }^{3}$.

For the on-orbit operations, to get around the absence of direct flow measurement for each plenum branch, the ESA Payloads Activation Ground Procedures verify the cooling resources availability during P/L activation by computing the WPA flow rate increase across the related WFSV opening. This verification step gives the go for the rack power on. Although at a first glance this approach seemed to be sufficiently accurate and simple for implementation into Procedures, during on-orbit activities, it was revealed to be the weak point of Payloads Activation as described in the next paragraph.

\section{On orbit anomalies on flow rate}

Columbus and its ISPR P/Ls on-orbit operations started in late February 2008, and the first low water mass flow rate anomaly occurred on March $3^{\text {rd }}$ of the same year. The Fluid Science Laboratory (FSL), located in the Overhead 1 position (O1) of Columbus, required by design a water flow rate of $170 \mathrm{~kg} / \mathrm{h} \pm 10 \%$, but after its activation the water flow increase - measured with the WPA Venturi flow meter - was only $144 \mathrm{~kg} / \mathrm{h}$. As preliminary assessment, it was agreed that the measured flow rate could not have been sufficient to provide the FSL rack with the necessary thermal heat rejection capability, and therefore its operations were initially stopped. However, after off-line engineering investigations, it was clarified that no anomaly on the ITCS water loop had occurred, and that the measured low flow rate was due to the inaccuracy of the Venturi flow meter. Based on this, further FSL operations were allowed.

After this first anomaly, further similar anomalies have been continuing to occur during activation of other ISPR $\mathrm{P} /$ Ls within Columbus, and temporary workarounds have been implemented in order to improve the water flow calculation (as described in section IV). However, even if these workarounds have been useful up to now to reduce the number of anomaly occurrences, they have not been sufficient to completely prevent them from happening.

The initial heavy operational impact (stopped payload operations) has been progressively reducing with time, as Columbus $\mathrm{P} / \mathrm{L}$ operators have been learning that the anomaly seems not to be directly related to an actual reduced water flow, but to inaccuracy in the measurement. At the time being, the real time reaction to this anomaly is a request by the operators to the ISPR developers to proceed with the activation with the measured flow rate, even if this is slightly lower than what required per procedure. In all cases up to present, the response has been positive, also based on the fact that the water loop temperature set point $\left(17^{\circ} \mathrm{C}\right)$ is lower than what is in the Payloads Interface Requirements Document ${ }^{4}\left(16-20^{\circ} \mathrm{C}\right)$, based on which the P/Ls heat rejection has been calculated. Therefore, no further ISPR activation has been stopped. However, even if reduced, a certain operational impact is still in place, due to the fact that payload activations get delayed for some time when the anomalies occur, because of the time needed for real-time coordination between payload developers, operators and NASA counterparts. 


\section{Engineering evaluations and follow on}

Engineering analysis has been performed on the activation telemetry data to fix the issue and provide countermeasures. Off-line investigations highlighted that the low mass flow rate estimation by the Flight Control Team (FCT) during Payloads' activations was, in most of "anomalous" cases, not a real issue as it could be related to the combined effect of some imprecise estimations.

In order to understand the issue it is necessary to synthetically describe the original version of Procedures used by FCT for Payloads Activation. Upon POIC Payload activation request FCT was requested to perform the following steps:

1. record WPA mass flow rate and put the value into variable $w_{\mathrm{OLD}}$;

2. fully open WFSV;

3. command WFSV to target position (possibly different from $100 \%$ open);

4. fine adjust WFSV (to reach target position or - for $100 \%$ position - in order to avoid sticking for endstroke position reaching);

5. record WPA mass flow rate and put the value into variable $w_{\mathrm{NEW}}$;

6. verify that $w_{\mathrm{NEW}}-w_{\mathrm{OLD}} \geq w_{\mathrm{CAL}}$ ( $w_{\mathrm{CAL}}$ is defined as the calibration mass flow rate at the calibration delta pressure);

7. if the verification at step 6 is not successfully, the activation is stopped until confirmation by POIC that no thermal issues are envisaged.

This approach is very simple to be executed, but as demonstrated, has several cons discussed in the next paragraphs.

\section{A. Time Averaging}

In the activation procedures, the FCT was not requested to average mass flow rate recordings in time, allowing, in principle, the calculation of delta mass flow rate from instantaneous data. The Venturi flow meter readings are noisy and using instantaneous data instead of time-averaged values often conducted to wrong estimations.

An example of this not correct approach is represented by BLB Activation on DOY98/2011 (AR-094). In this case BLB mass flow rate was estimated in real-time to be about $146 \mathrm{~kg} / \mathrm{h}$. Evaluation of delta mass flow (on the basis of telemetry data) calculating " 5 -minutes averaged values" demonstrated that real mass flow increasing through WPA was no less than $151 \mathrm{~kg} / \mathrm{h}$.

Delta mass flow computed on averaged data gave a higher delta mass flow figure w.r.t. that reported in the Anomaly Report (AR). Even so, the new value is still below the minimum ICD figure of $155 \mathrm{~kg} / \mathrm{h}$ : the time average effect on the estimation was identified as one of the possible causes for the anomaly but not the only one.

In Figure 3 are shown the Mass Flow Rate and WFSV telemetry data for a 5-minutes stable period in DOY56/2010: while valve position indicator is stable, Mass Flow Rate readings from Venturi oscillates significantly; its punctual use for delta mass flow computations is not reliable.

As a countermeasure into Payloads Activation Procedures, a minimum 5-minutes average period was introduced for evaluating current mass flow rate. 


\section{B. Thermal-hydraulic stabilization}

The anomalous Payloads activations gave the opportunity to observe another phenomenon usually not properly taken into account during the activity, i.e., the ACTS hydraulic stabilization, whatever is causing the transient.

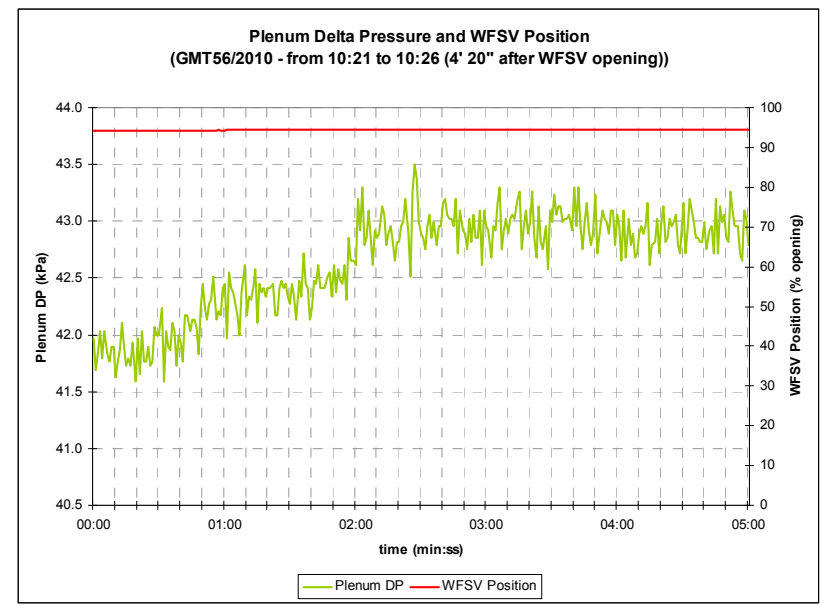

Figure 4 Plenum Delta Pressure and WFSV position (DOY56/2010) 4' 20"' after WFSV opening

If a hydraulic transient is occurring in the ATCS and the Plenum Delta Pressure temporary goes out of the dead band, the WPA control law reacts modifying the motor speed in order to restore Plenum Delta Pressure into nominal range. Although this control law reaction time is very fast (on the order of seconds), such a hydraulic transient could cause a thermal transient for Plenum/CHX temperature changes and subsequent WMVs adjustment: these secondary transients are not as fast as hydraulic transients and can be considered extinguished only after some minutes. A correct calculation of average mass flow rate should take into account also this secondary effect. In the following a significant example is reported.

On DOY 56/2010 proper WFSV was commanded to open at 10:16:19 and was fine adjusted at 10:18:01 for BLB Operations. After 4' 20" from WFSV opening, ATCS loop was not yet hydraulically and thermally stable; Plenum Delta Pressure was increasing only for WMVs movement due to thermal stabilization. In order to estimate stabilization of the signal, a cumulative average is plotted. In this way it is possible to judge if a transient is still in progress or not.

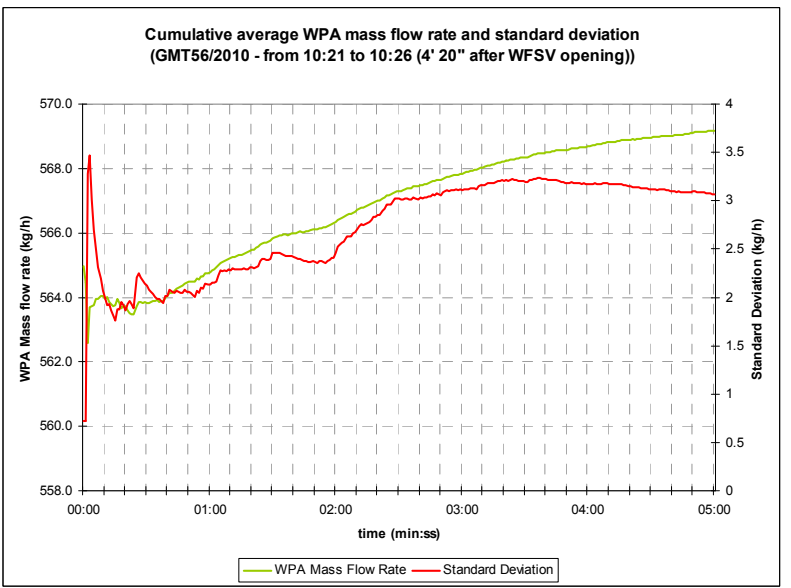

Figure 5 Cumulative average mass flow rate and standard deviation during a thermal transient on DOY56/2010

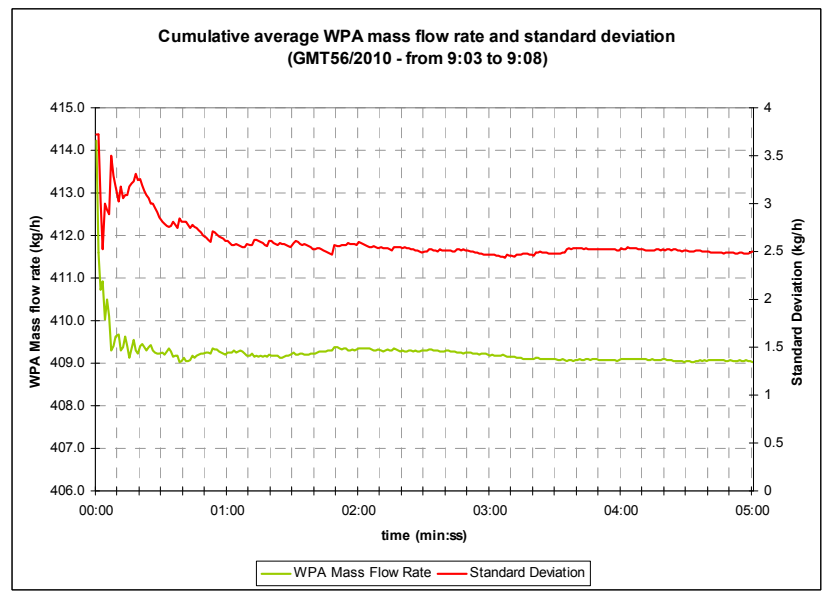

Figure 6 Cumulative average mass flow rate and standard deviation when no any thermal transient is happening (DOY56/2010)

In the graph above an example is reported in which:

- no any WFSV was moving;

- the calculation of WPA mass flow averaging on 1 or 5 minutes does not give the same result; the same for Plenum Delta Pressure;

- the standard deviation on mass flow rate was very low (about $3.0 \mathrm{~kg} / \mathrm{h}$ after 5 minutes).

This demonstrates clearly that a 5-minutes average estimation for WPA mass flow rate in an unstable system $(\Delta \mathrm{P}$ is increasing/decreasing - even inside control dead band - or when WFSV/WMV adjustment is occurring) conducts to a calculation affected by a significant error (in this case about $6 \mathrm{~kg} / \mathrm{h}$ ). 
On the contrary when no transient is occurring, 1-minute averaging is representative for the hydraulic parameters (Figure 6).

\section{Different Plenum $\triangle P$ "prior to" and "after" WFSV opening}

During $\mathrm{P} / \mathrm{Ls}$ activations it a nominal behavior was observed that could be an additional explanation for anomalies rising.

Let's assume that ATCS is currently running and guarantees $42 \mathrm{kPa}$ at Plenum. When a WFSV is open, Delta Pressure suddenly drops. When Delta Pressure goes out of dead band range, WPA control law reacts in order to increase motor speed and restore Delta Pressure across the Plenum. Generally it has been observed that final pressure (after WFSV opening and once the hydraulic transient has extinguished) is lower than the initial one. For this reason the mere calculation of mass flow rate through the $\mathrm{P} / \mathrm{L}$ as across the pump cannot be considered reliable.

In order to take into account the difference of Plenum Delta Pressure during P/L activation, an analytical correction has been proposed to the FCT and has been implemented into Procedures.

Let's assume that a hydraulic system is initially controlled at a differential pressure of $\Delta p_{\mathrm{i}}$ and is flowed by a mass flow rate of $W_{\mathrm{i}}$; when the differential pressure varies from $W_{\mathrm{i}}$ to $W_{\mathrm{f}}$, if resistance remains the same, the following formula are applicable:

$$
\begin{aligned}
\Delta p=\frac{1}{2} k_{l o c} \cdot \rho \cdot u^{2} & =\frac{1}{2 \rho} k_{l o c} \cdot G^{2}=\frac{1}{2 \rho} k_{l o c} \cdot\left(\frac{W}{A}\right)^{2} \\
\Delta p_{f} & =\frac{1}{2 \rho} k_{l o c} \cdot\left(\frac{W_{f}}{A}\right)^{2} \\
\Delta p_{i} & =\frac{1}{2 \rho} k_{l o c} \cdot\left(\frac{W_{i}}{A}\right)^{2}
\end{aligned}
$$

and so

$$
\begin{gathered}
\frac{\Delta p_{f}}{\Delta p_{i}}=\left(\frac{W_{f}}{W_{i}}\right)^{2} \\
W_{i}=\sqrt{\frac{\Delta p_{i}}{\Delta p_{f}}} \cdot W_{f}
\end{gathered}
$$

Based on formula (5) it is possible to evaluate mass flow rate through a rack at the same delta pressure in order to avoid an underestimation of mass flow rate through the rack.

\section{WPA Venturi readings uncertainty}

As explained above, the only way to quantify the water flow rate provided by the WPA is the Venturi flow meter inside the assembly; in order to understand if a real issue was present or not, a review of Venturi performances - on the basis of literature from $\mathrm{C} / \mathrm{D}$ phase - was performed.

The purpose of that sensor was purely monitoring and not for precise measuring of water flow variations during water loop reconfigurations; it was implemented in the WPA as housekeeping sensor and not to determine the P/L flow rate. Otherwise, as mentioned into the "WPA measurement and command list" document ${ }^{5}$, the accuracy of the sensor is $3 \%$ of full scale for the entire acquisition chain. As full scale is $1200 \mathrm{~kg} / \mathrm{h}$, the accuracy on the single reading is the current value $\pm 36 \mathrm{~kg} / \mathrm{h}$; this demonstrates that in all so-called anomalous activations, flow rate was inside the inaccuracy range.

Moreover it is worth to notice that the measurement refers to the water flowing through the WPA and the increase of water flow can be distributed also between the cold plate branches and between other $\mathrm{P} / \mathrm{L}$ branches already fluxed and not entirely attributed to the last open branch. 


\section{E. Water Flow Selection Valve opening position}

General approach to consider WSFV fully open was based both on the Status indicator and on Position indicator. For European P/Ls, in order to verify that WFSV was fully open, the two conditions had to be verified:

- the so called Open Status telemetry variable assuming the OPEN value

- the position indicator value higher than $97 \%$

The first verification was successful whenever WFSV was requested to open; on the contrary the second one was unsuccessful for some WFSVs.

This anomalous behavior was not initially recognized as significant, but based on WFSV ground tests data, gave another input for the anomaly comprehension. During most of the anomalous activations (especially for EDR and BLB) related WFSV was open with a position indication lower than $97 \%$.

The fact that WFSV is not completely open has an effect on mass flow rate through the rack as documented in ground tests for WFSV Final Hydraulic Characterization ${ }^{6}$. This effect, although secondary (the effect in terms of mass flow rate reduction has been estimated to be no more than $5 \mathrm{~kg} / \mathrm{h}$ ) could have contributed to the occurrence of the issue.

\section{F. HRFs measurement on mass flow rate}

In order to evaluate Venturi sensor readings accuracy it was taken the advantage of HRF $1 \& 2$ flow measurements retrieved for CRS5 to CRS6 upgrade verification ${ }^{7}$, to check the approach for P/Ls flow rate measurement using the WPA delta flow rate. Two significant examples analyzed are reported: HRF-1 activation on DOY 300/2009 and HRF-2 operations on DOY 303/2009.

GMT 300-2009 - HRF1 Activation

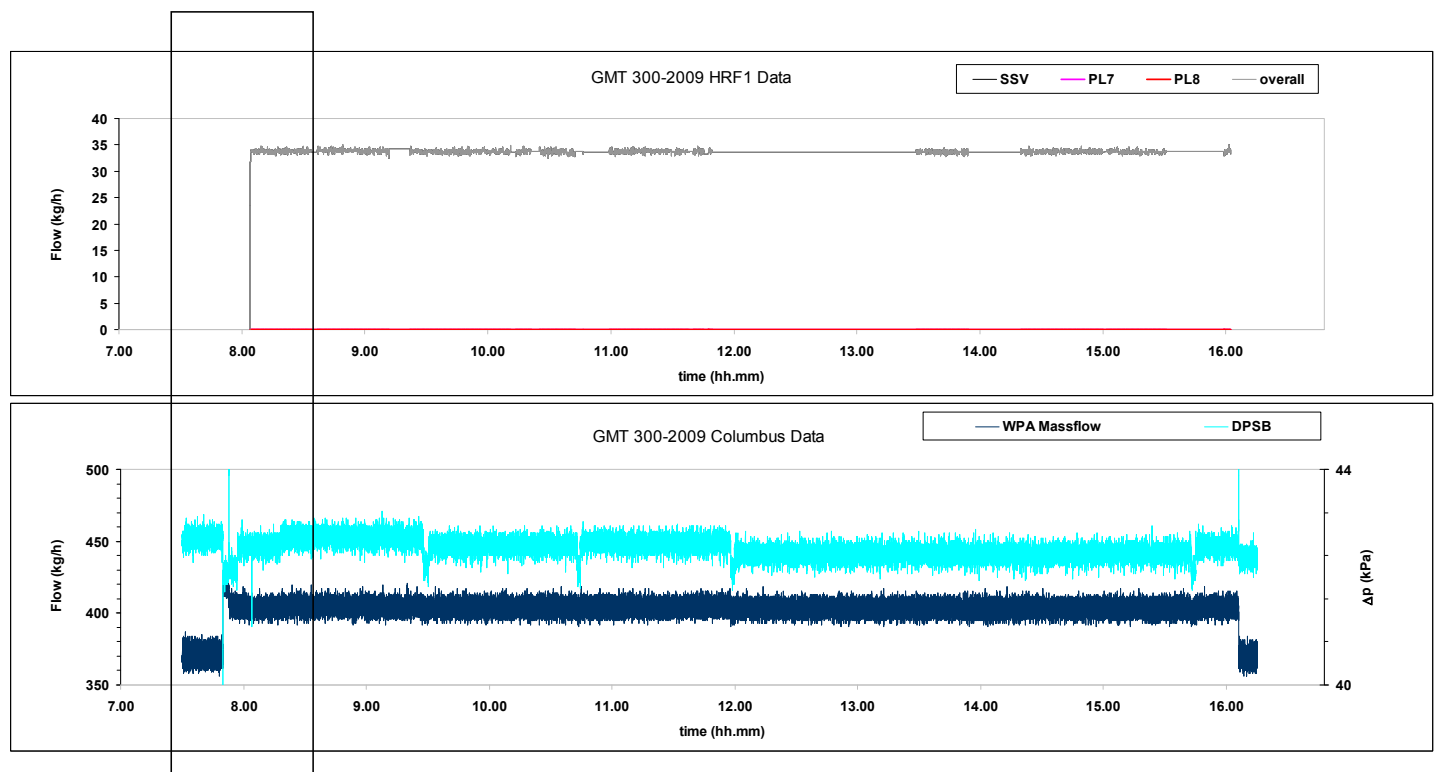

Figure 7 WPA and HRF-1 internal flow-meter data for DOY300/2009 HRF-1 activation 


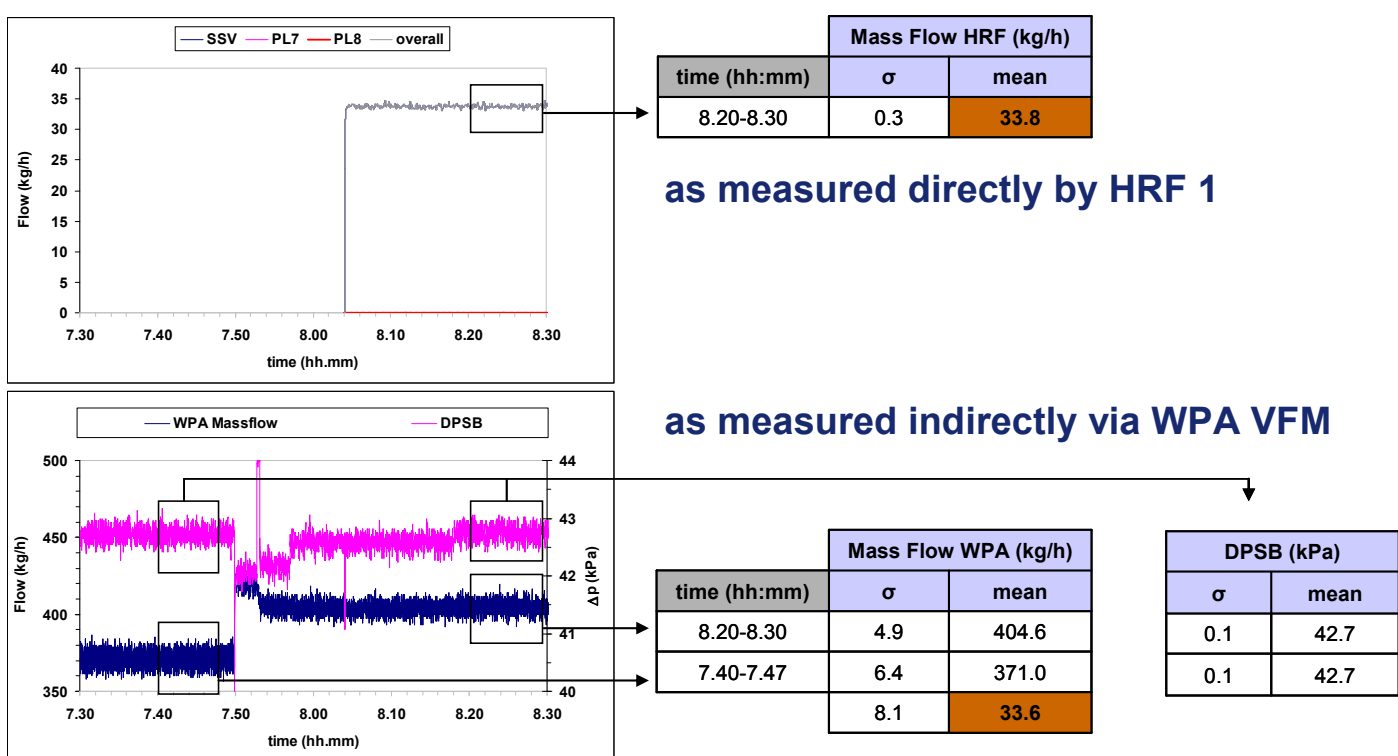

Figure 8 WPA and HRF-1 data evaluations on DOY300/2009 HRF-1 activation

The following points were highlighted:

- measurement accuracy of WPA Venturi Flow Meter $(\sigma=8.3)$ is about one order of magnitude in front of HRF flow sensor $(\sigma=0.3)$;

- even so a good value is computed $(33.8$ vs $33.6 \mathrm{~kg} / \mathrm{h})$, well within the HRF standard deviation

It was finally noticed that this result for P/L's activation was mainly related to the fact that time frames selected to compute mean values were large enough (in this case higher than 7 minutes) over a stable range and at the same Plenum Delta Pressure $(42.7 \mathrm{kPa})$.

GMT 303-2009-HRF2 Operations

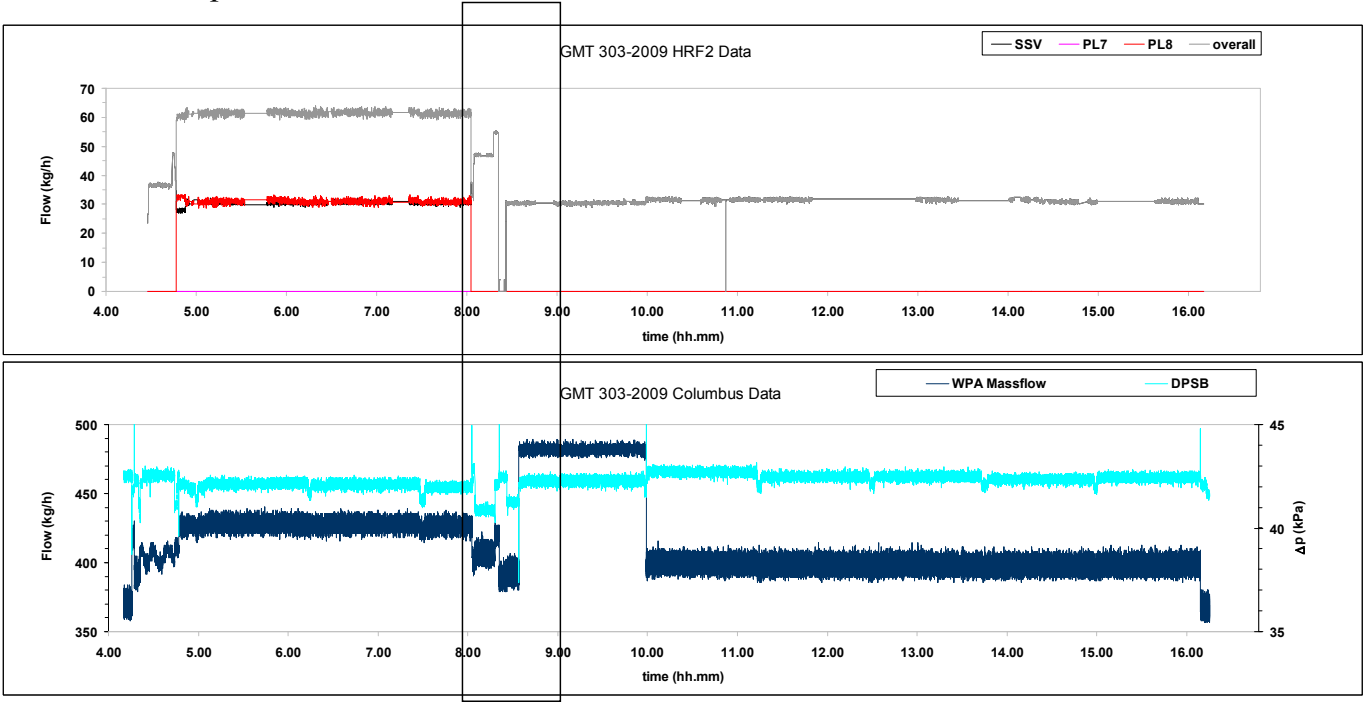

Figure 9 WPA and HRF-2 internal flowmeter data during DOY303/2009 HRF-2 operations 


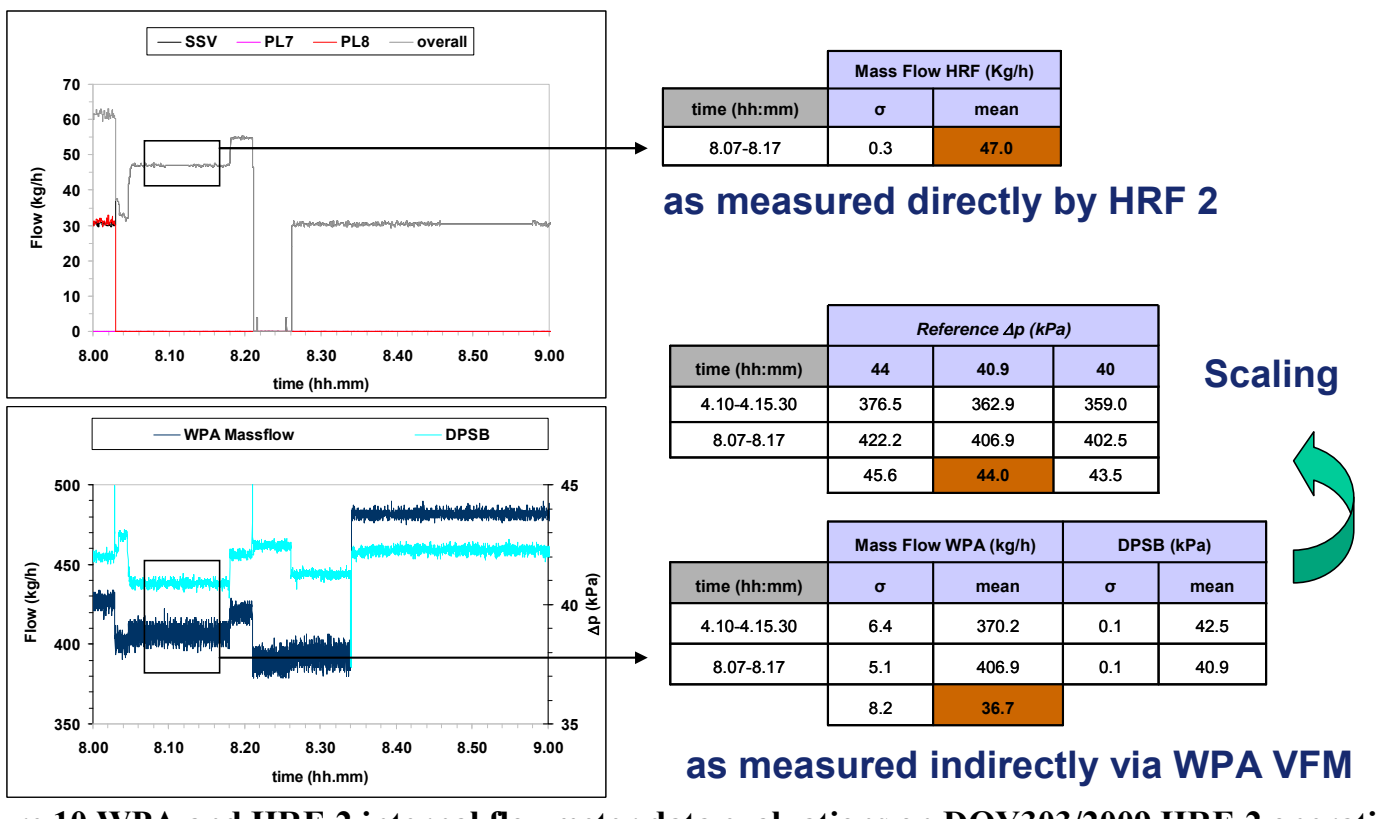

Figure 10 WPA and HRF-2 internal flowmeter data evaluations on DOY303/2009 HRF-2 operations

Conversely, in this last case, the following points were highlighted:

- WPA Venturi Flow Meter flow rate estimation was $10.3 \mathrm{~kg} / \mathrm{h}$ below HRF-2 measurement;

- the Plenum Delta Pressure across the P/L changed - during the operations - by $1.6 \mathrm{kPa}$ (42.5 vs $40.9 \mathrm{kPa}$ );

- by scaling the flow rates at $\Delta \mathrm{P}=42.1 \mathrm{kPa}$ (at which HRF-2 performed its measurement) the error reduced to $3 \mathrm{~kg} / \mathrm{h}$;

- even scaling at maximum $\Delta \mathrm{P}=44 \mathrm{kPa}$, the WPA Venturi Flow Meter prediction $(45.6 \mathrm{~kg} / \mathrm{h})$ is below the one measured at $40.9 \mathrm{kPa}(47 \mathrm{~kg} / \mathrm{h})$

Concluding the comparison between HRF-1 and HRF-2 internal flow meters and WPA Venturi Flow Meter indirect measurements showed that, for the selected cases:

- differences between two measurements are strongly related to the relevant Plenum Delta Pressure;

- scaling the measurement with the quadratic (turbulent) law $\Delta p \propto f l o w^{2}$ provides a better estimation.

\section{Ultrasonic Flow Meter Test}

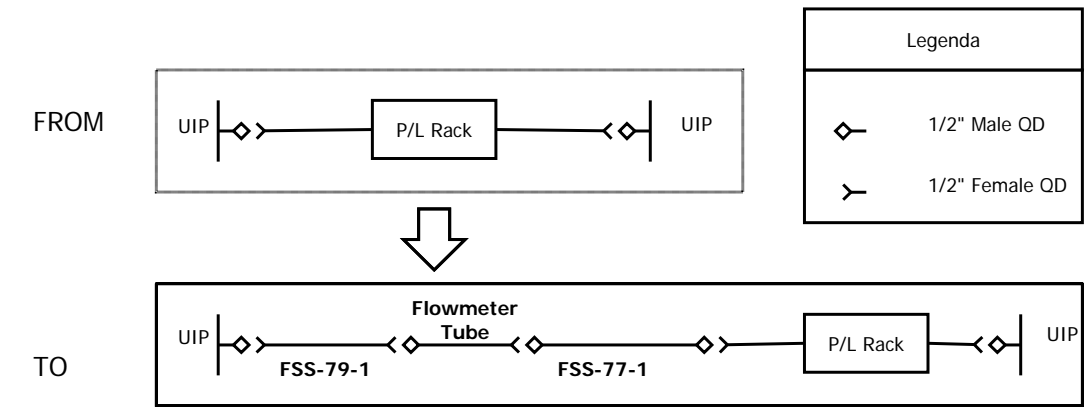

Figure 11 Configuration for flow measurement test with US UItrasonic Flow Meter
In order to verify mass flow rate through some racks (FSL, EDR and ER-3) an on-orbit test to be performed with the NASA Ultrasonic Flow Meter has been proposed. The flow meter is modified Commercial Off-The Shelf (COTS) hardware which uses ultrasonic signals to measure the flow rate through a non-intrusive, clamp-on transducer. The flow meter and transducer are shown in Figures 12 and 13. If a sufficient 
length of rigid tubing is accessible, the transducer can be clamped directly to the system plumbing. However, if a straight section of rigid plumbing is not present or inaccessible, a "Flowmeter Tube," which is simply a straight tube with self sealing QDs, can be installed to provide the necessary rigid attachment location for the transducer.

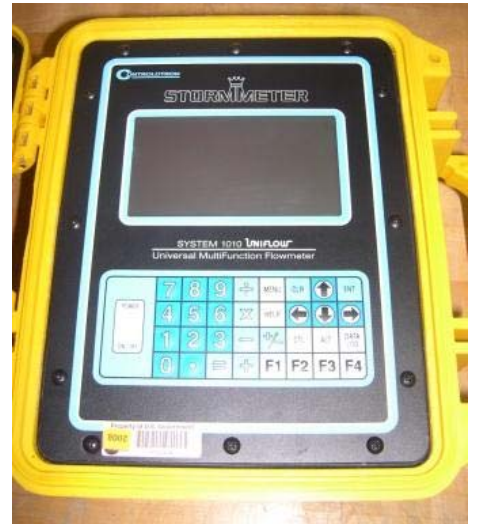

Figure 12 Ultrasonic Flow Meter

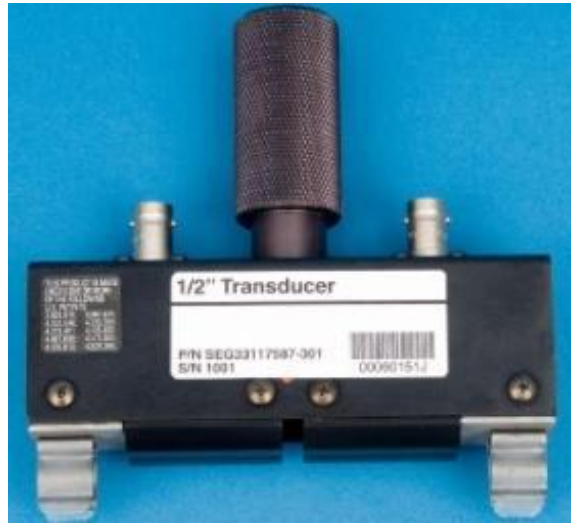

Figure 13 Transducer

The hydraulic impact of its installation across the $\mathrm{P} / \mathrm{L}$ inlet line (Figure 11) has been preliminarily investigated by analysis with the aim of the THMM. Hydraulic loss of the set-up was derived taking into account flex hose data provided by NASA, together with contribution of the additional QDs and flow meter rigid tube. The effect, in terms of variation on water flow, has been estimated to be no more than $3 \%$

of flow rate.

Set-up configuration with the non-intrusive ultrasonic flow meter in line with the $\mathrm{P} / \mathrm{L}$ was derived from the US LAB procedure "LAB MFCV Adjustment and Node 1 RFCA Accuracy Verification using non-intrusive Flow Meter", consisting of:

- $\quad$ a $1 / 2$ " PTFE flex hose, the FSS-77-1, $0.457 \mathrm{~m}$ long;

- a $1 \frac{1}{2}$ " Metal flex hose, the FSS-79-1, 1.524 m long;

- $\quad a^{1 / 2 "}$ " rigid tube on which is mounted the flow meter.

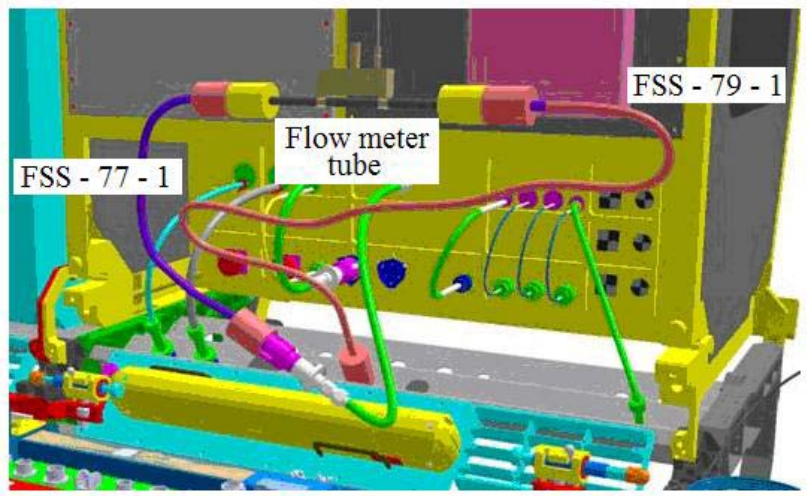

Figure 14 Setup configuration for flow measurement test with US Ultrasonic Flow Meter
From an operational standpoint the test sequence itself proposed was intended to verify on-orbit the impact of the added UFM on flow rate.

The carried out analyses have concerned the FSL rack only, with rack calibration flow rate of $170 \mathrm{~kg} / \mathrm{h}$. Relevant WFSV position was changed from completely closed to completely open. By comparing the same simulations performed with and without flow meter set-up, the flow rate on payload line is slightly decreased, with a maximum reduction of about $3 \%$. Therefore, it is evident the flow meter set-up can be acceptable because the impact on the original payload flow rate is minimum and can be used to verify $\mathrm{P} / \mathrm{L}$ flow rate.

To limit crew time and test duration measurements will be performed on ER-3, FSL, EDR and BLB.

ER-3 data will be used to verify the flow meter set-up impact on the measurement (comparing avionic flow rate measured by the ER-3 and ultrasonic flow meter prior and after ultrasonic set-up installation) and the accuracy of the ultrasonic flow-meter itself. ER-3 shall be configured with the avionic branch fully open and EMCS branch closed. Finally, in order to limit the effect of Plenum Delta Pressure variation during WFSV opening, it is under evaluation the possibility to change Plenum Delta Pressure control law dead band from current $\pm 2.0 \mathrm{kPa}$ to \pm 0.6 $\mathrm{kPa}$. 


\begin{tabular}{|c|c|}
\hline ID Step & Description of the step \\
\hline (1) & Flow meter preparation for first use (battery charging, jumper filling, etc.) \\
\hline$(2)$ & Perform switchover from WPA1 to WPA2 \\
\hline (3) & Change WPA1 DP Plenum Control Law Parameters \\
\hline (4) & Perform switchover from WPA2 to WPA1 keeping the WPA1 EU active \\
\hline (5) & Open WFSV A1 with final adjustment and perform ER-3 Activation \\
\hline (6) & Wait for hydraulic stabilization \\
\hline (7) & Record ER-3 flow-meter reading \\
\hline (8) & Perform ER-3 Deactivation and close WFSV A1 \\
\hline (9) & Installation of the ultrasonic flow meter to A1 location \\
\hline$(10)$ & Open WFSV A1 and perform ER-3 Activation \\
\hline (11) & Wait for hydraulic stabilization \\
\hline (12) & Record ER-3 flow-meter reading \\
\hline (13) & Crew takes reading of ultrasonic flowmeter and reports back to Col-CC \\
\hline$(14)$ & Perform WFSV A1 fine adjustment \\
\hline$(15)$ & Wait for hydraulic stabilization \\
\hline$(16)$ & Record ER-3 flow-meter reading \\
\hline$(17)$ & Crew takes reading of ultrasonic flowmeter and reports back to Col-CC \\
\hline (18) & Perform ER-3 Deactivation and WFSV A1 closure \\
\hline$(19)$ & Disconnection of the ultrasonic flow meter from A1 and connection to O1 location (FSL) \\
\hline$(20)$ & Open WFSV O1 \\
\hline (21) & Wait for hydraulic stabilization \\
\hline (22) & Crew takes reading of ultrasonic flowmeter and reports back to Col-CC \\
\hline$(23)$ & Perform WFSV O1 fine adjustment \\
\hline$(24)$ & Wait for hydraulic stabilization \\
\hline$(25)$ & Crew takes reading of ultrasonic flowmeter and reports back to Col-CC \\
\hline (26) & Close WFSV O1 \\
\hline (27) & Repeat steps $19 \div 26$ for F1 (EDR) \\
\hline (28) & Disconnection of the ultrasonic flow meter from F1 and connection to A2 location (BLB) \\
\hline$(29)$ & Open WFSV A2 \\
\hline$(30)$ & Wait for hydraulic stabilization \\
\hline$(31)$ & Crew takes reading of ultrasonic flowmeter and reports back to Col-CC \\
\hline (32) & Perform WFSV A2 fine adjustment \\
\hline (33) & Wait for hydraulic stabilization \\
\hline$(34)$ & Crew takes reading of ultrasonic flowmeter and reports back to Col-CC \\
\hline$(35)$ & Open WFSV O1 with fine adjustment \\
\hline$(36)$ & Wait for hydraulic stabilization \\
\hline (37) & Crew takes reading of ultrasonic flowmeter and reports back to Col-CC \\
\hline (38) & Close WFSV $\mathrm{O} 1$ and A2 \\
\hline (39) & Disconnection of the ultrasonic flow meter from A2 \\
\hline$(40)$ & Perform switchover from WPA1 to WPA2 to reset automatically WPA1 DP Plenum control law parameters \\
\hline$(41)$ & Perform switchover from WPA2 to WPA1 \\
\hline
\end{tabular}

Table 1 -Proposed sequence for Ultrasonic Flowmeter Test 


\section{Conclusion}

The extended analysis on on-orbit anomalies on mass flow rate issue demonstrated some limitation on the methodology for payload flow rate estimation being affected by more than one criticality.

a) As short term/real time solution payloads developers were requested to verify - case by case - the capability to operate in such possible low flow rate conditions;

b) as mid term solution a set of changes on activation procedures was proposed in order to limit the anomaly rising only to real issues; a list of these countermeasures is below:

- calculating delta mass flow on average (minimum 5 minutes) WPA flow readings;

- waiting for loop stabilization (in terms of Plenum Delta Pressure and WPA mass flow rate) taking into account that also WFSV fine adjustment commands can be effective on flow rate; for this reason the calculation should start at least 5 minutes later than the last WFSV adjustment;

- using a corrective factor for mass flow who take care of different Plenum Delta Pressure prior and after WFSV opening;

- taking care of WFSV real position (WFSV indicating an OPEN status could be not hydraulically completely open);

- changing some verification steps for mass flow rate increasing during Payloads' activation

c) As long term solution an on-orbit test with NASA Ultrasonic Flow meter has been proposed with an optimized test sequence which guarantees to drive away any suspect on ATCS cooling capability for Payloads.

\section{Acknowledgments}

We wish to thank and acknowledge the professional support of all the team involved in the Columbus Operations. A particular thanks goes to Massimo Antonacci (TAS-I), Eugenio Gargioli (TAS-I), Donata Pietrafesa (Sofiter System Engineering), Alessandro Nocera (Aviospace - EADS Astrium), Marco Bruno (EADS Astrium) and Simon Challis (EADS Astrium).

\section{References}

\footnotetext{
${ }^{1}$ ESATAN-FHTS ${ }^{\mathrm{TM}}$, Ver.10.2, Software Package, ITP Engines UK, 2010, URL: http://www.itp-engines.co.uk/

${ }^{2}$ APM ATCS Thermal and fluidic analyses and THMM report, CLT-RP-AI-0019, February 2000

${ }^{3}$ S. De Palo, P. Vaccaneo, “ATCS Re-certification test: the investigation of Columbus MT loop performances close and beyond its maximum operative limits", Proceeding of $36^{\text {th }}$ ICES conference, SAE, 2006

${ }^{4}$ Columbus Pressurized Payloads Interface Requirements Document, COL-RIBRE-SPE-0164, November 2010

${ }^{5}$ Columbus - PICA measurement and command list, COL-LI-AI-0022, April 2003

${ }^{6}$ WFSV Final Hydraulic Characterization Test Record Sheet, COL-RIBRE-TRS-PFM-642, March 2007

7 S.De Palo, B.D. Wright et al "Updates on HRF Payload Operations in Columbus ATCS", Proceeding of $41^{\text {st }}$ ICES conference, AIAA, 2011
} 